\title{
Antinuclear Antibodies Patterns in Patients with Celiac Disease
}

\author{
Rosane Mansan Almeida ${ }^{1}$, Zita Dinis Lopes da Silva² ${ }^{2}$ Franco Batista Leite ${ }^{3}$ and Yanna Karla de Medeiros Nóbrega*1,2 \\ ${ }^{1}$ Applied laboratory analysis, Brazil
}

${ }^{2}$ Department of Pharmaceutical Sciences, Brazil

${ }^{3}$ Clinical analysis laboratory, Brazil

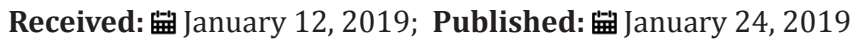

*Corresponding author: Yanna KM Nóbrega, Department of Pharmaceutical Sciences, Brazil

\begin{abstract}
Background: Celiac disease (CD) is a chronic immune-mediated disorder triggered by gluten ingestion in genetically susceptible individuals and its coexistence with other autoimmune disorders is well documented. Antinuclear antibodies (ANA) has been used as a tool for screening and following individuals with connective tissue autoimmunity. Aim: The aim of this study was to evaluate the frequency of ANA and its respective staining patterns in the serum of patients with biopsy-proven CD collected at the moment of diagnosis.

Methods: Sera from 161 biopsy-proven celiac individuals (103 females; mean age $17 \pm 14$ years) were assayed for the presence of ANA by immunofluorescence methodology, using HEp-2 cells substrate.

Results: Out of the 161 samples, 14 (8.7\%) tested positive for ANA. All positive sera presented nuclear staining patterns, subdivided in three distinct groups: homogeneous nuclear, nuclear fine speckled and nuclear coarse speckled.

Conclusion: CD biopsy-proven patients can present ANA positive tests. ANA test in CD individuals may be useful as a screening approach to evaluate at-risk individuals for developing other disorders or a marker of the adaptive autoimmunity in $\mathrm{CD}$. The actual meaning of ANA positivity among CD individuals is yet to be understood.
\end{abstract}

Keywords: Hep-2 Cells; Nuclear Staining Pattern; Indirect Immunofluorescence Assay

Abbreviations: CD: Celiac Disease; ANA: Antinuclear Antibodies; SLE: Systemic Lupus Erythematosus; IIF: Indirect Immunofluorescence; HN: Homogeneous Nuclear; NFSP: Nuclear Fine Speckled Pattern; NCSP: Nuclear Coarse Speckled Pattern

\section{Introduction}

Celiac disease (CD) is a chronic multisystem disorder triggered by gluten ingestion in genetically susceptible individuals $[1,2]$. The intestine is the primary affected site. Typical lesions are characterized by increased intraepithelial lymphocytes, crypt hypertrophy and progressive villous atrophy [3,4] resulting in malabsorption, diarrhea, bloating and to variable degrees of undernutrition. Although triggered by a dietary antigen, it shows many autoimmune characteristics, such as the presence of high titers of anti-tissue transglutaminase 2 autoantibodies produced in the small intestinal mucosa [5]. Similar to other autoimmune disorders, $\mathrm{CD}$ has a higher prevalence in females, with a female: male ratio of 2:1. It has been suggested that lengthier exposure to gluten in celiac patients may increase the risk of other autoimmune diseases, i.e., the more advanced is the patient's age at CD diagnosis, the higher would be the chance of presenting or developing another autoimmune disorder [6,7]. However, older age at diagnosis may be a bias since the prevalence of some autoimmune diseases and also CD tend to increase with aging $[8,9]$.

Even though intestinal biopsy is still considered the gold standard for CD diagnosis in adults, serological tests are crucial in determining who should undergo the procedure [10]. The antiendomysium-IgA (IgA-EMA) and anti-transglutaminase-IgA (IgA-tTG) tests are the most widely used, with sensitivity and specificity approaching 100\% [2,11-13]. Evaluation of antinuclear antibodies (ANA) has been used as a complementary tool following clinical suspicious for screening, diagnosing and establishing the treatment of some autoimmune diseases, especially systemic lupus erythematosus (SLE) and rheumatic disorders, being a negative 
value a strong evidence against active autoimmunity [14]. However, ANA positivity by itself cannot be interpreted as pathognomonic of any specific disorder nor as indicative of an underlying autoimmune disease, once those antibodies may be present up to $26 \%$ of the general population, especially among females and the elderly [1517]. Some years ago, Human Epithelioma cells (HEp-2 cells, derived from human larynx carcinoma) were introduced as substrate for indirect immunofluorescence (IIF) assays, once they proved to be an excellent substrate of a large amount of auto-antigens. HEp2 cells increased sensibility and specificity to ANA tests. ANA detection by IIF also has the advantage of obtaining information on the IIF staining pattern, which can improve its clinical value.

Beside nuclear patterns, cytoplasmic and mitotic cell patterns can also be recognized. In fact, the term anti-cellular antibodies has been suggested to rename these autoantibodies $[18,19]$. Recently, the patterns of antinuclear antibodies in HEp-2 cells had their nomenclature standardized [20]. The reference standards are available free of charge to clinical laboratories and researchers. It is hoped that standardization lead to a better understanding of the relationship between ANA and autoimmune diseases. Currently, some ANA staining patterns are highly associated with particular diseases, such as anti-DNA and anti-Sm antibodies with SLE or antitopoisomerase I antibodies with progressive systemic sclerosis. Thus, ANA can be useful biomarkers for diagnosis [21]. Moreover, besides the diagnosis, ANA may have value in the prognostic role in certain clinical settings. For example, presence of the ANA with fine-speckled and nucleolar pattern has been associated with a more advanced stage of microvascular damage in sclerosis patients [22]. Considering that ANA may be present in the sera of individuals with autoimmune diseases, the aim of this study was to investigate the frequency of ANA and its respective staining patterns in the serum of patients with biopsy-proven CD collected at the moment of diagnosis.

\section{Methods}

\section{Study Group}

Sera from 161 biopsy-proven celiac individuals (103 females; mean age $17 \pm 14$ years; age range 1 to 77 years at diagnosis), diagnosed at the Celiac Disease Research Laboratory of the University of Brasilia School of Medicine were analyzed. Sera samples were obtained at the time of diagnosis and maintained at $-20 \stackrel{\circ}{\circ}$. For this study they were assayed for the presence of ANA by IIF methodology with HEp-2 substrate (ByoSystems kits; Barcelona, Spain). All positive samples were retested and results were confirmed using INOVA Diagnosis kit (San Diego USA). The study is in accordance with the principles of the latest Declaration of Helsinki (2008) and was approved by the Ethical Committee of the Brasilia University School of Health Sciences. All eligible patients were informed about the objectives of the research and written informed consent was obtained from each patient.

\section{Immunofluorescence}

Serum samples went through 1:40 dilution in PBS, pH 7.2; then distributed on slides with HEp-2 cells, with positive and negative controls for test validation; and then incubated in a moist chamber during 30 minutes at room temperature. Slides were subsequently washed twice during 5 minutes in PBS and, after dried, incubated with $50 \mu \mathrm{L}$ of fluorescein isothiocyanate-conjugate goat anti-human IgG during 30 minutes in a dark chamber. The five-minute washing step was repeated twice and slides were then dried and assembled with $78 \%$ glycerol and coverslip. Analysis were performed by two independent experts using an Axiophot 2 Zeiss microscope under fluorescent light at 400x magnification. The serum samples were processed twice, using two different commercial kits, in two stages: a preliminary screening stage during which all samples were diluted and assayed and a second stage of titration during which the positive samples were titled to a maximal dilution of 1:640.

\section{Results}

Out of the 161 samples, 14 (8.7\%) tested positive for ANAHEp-2. Ten of them (71.4\%) were from females (mean age: 22 $\pm 16 \mathrm{yr}$; age range: 1 to $44 \mathrm{yr}$ ) and four (28.6\%) were from males (mean age: $22 \pm 18 \mathrm{yr}$; age range: 2 to $43 \mathrm{yr}$ ). All tested sera presented nuclear pattern, subdivided in three distinct groups (Table 1). The respective ANA titers found in the positive samples are presented as pattern profiles and titration for each gender (Table 2). Only titers equal or higher than 1:80 were considered significant. Table 1: Nuclear patterns found in ANA-Hep-2 sera from celiac patients.

\begin{tabular}{|c|c|c|c|}
\hline Pattern & Code* & Frequency & Percent (\%) \\
\hline Homogeneous Nuclear (HN) & AC-1 & 6 & 42.8 \\
\hline Nuclear Fine Speckled Pattern (NFSP) & AC-4 & 7 & 50.0 \\
\hline Nuclear Coarse Speckled Pattern (NCSP) & AC-5 & 1 & 7.2 \\
\hline Total & & 14 & 100 \\
\hline
\end{tabular}

Note: *ICAP (International Consensus on ANA patterns) codes.

Table 2: Relationship between titration and pattern presented in positive samples, evaluated according to the gender.

\begin{tabular}{|c|c|c|c|c|c|c|c|}
\hline \multirow{2}{*}{ Sex } & \multirow{2}{*}{ Pattern } & & & \multicolumn{2}{|c|}{ Titer } & \multirow{2}{*}{ Total } \\
\cline { 2 - 7 } & & Code* & $\mathbf{1 : 8 0}$ & $\mathbf{1 : 1 6 0}$ & $\mathbf{1 : 3 2 0}$ & $\mathbf{2 1 : 6 4 0}$ & 2 \\
\hline Female & Homogeneous Nuclear (HN) & AC-1 & 1 & - & - & \\
\hline & Nuclear Fine Speckled Pattern & & & & & \\
\hline (NFSP) & AC-4 & & 3 & 1 & & & \\
\hline
\end{tabular}




\begin{tabular}{|c|c|c|c|c|c|c|}
\hline- & 3 & $7(50.0 \%)$ & & & \\
\hline Male & Homogeneous Nuclear (HN) & AC-1 & - & - & - & 3 \\
\hline $\begin{array}{c}\text { Pattern } \\
\text { (NCSP) }\end{array}$ & Nuclear & Coarse & Speckled & & & $3(21.4 \%)$ \\
\hline Total & AC-5 & - & - & - & 1 & $1(7.2 \%)$ \\
\hline
\end{tabular}

\section{Discussion}

In this study we investigated the frequency of ANA positivity and its respective staining patterns in individuals with biopsyproven CD. ANA were found in $8.7 \%$ of our sample. This frequency is similar to that found in some studies $[23,24]$. Although a recent study in Italy [25] showed a higher proportion of individuals with CD testing positive for ANA - reaching $24 \%$ of the sample the studied population presented an older mean age (40.1 \pm 12.3 years) and was predominantly constituted by females (91/101). Those authors also found a positive correlation between ANA positivity and HLA DQ2/DQ8 haplotypes, which were present in all individuals with CD and in 49 out of the 59 individuals with nonceliac wheat sensitivity who tested positive for ANA (odds ratio $3.5,95 \%$ confidence interval). The different frequencies found among the studies could be associated to the presence of other autoimmune diseases in some studied patients. The coexistence of $\mathrm{CD}$ and other autoimmune diseases is well recognized, such as type 1 diabetes mellitus [4,26] Sjögren syndrome [27], autoimmune thyroid diseases [28] and connective tissue disorders. Less frequent association has been observed with Addison's disease [29], chronic autoimmune hepatitis [30], primary biliary cirrhosis [31,32] and systemic lupus erythematosus [33,34].

The common genetic origin of different autoimmune diseases are explained by linkage studies showing that certain chromosomal regions seem to confer predisposition to multiple immune disorders, thereby supporting the hypothesis which proposes the existence of groups of genes predisposing individuals to spectra of autoimmune diseases [35,36]. Another important point to be considered is the ANA staining pattern profile. Currently, specific ANA patterns are assigned to several autoimmune conditions. However, many studies involving ANA are still performed by other methods than IIF, making difficult to compare the results. Three nuclear patterns in HEp-2 cells were found here: homogeneous nuclear (HN), nuclear fine speckled pattern (NFSP) and nuclear coarse speckled pattern (NCSP). These patterns have been associated, respectively, with SLE and juvenile idiopathic arthritis (HN); Sjögren's Syndrome, SLE and Dermatomyositis (NFSP); and Mixed Connective Tissue Disease and Systemic Sclerosis (NCSP) (Chan). We demonstrated here that these ANA patterns also can be found in CD patients. We also demonstrated that ANA patterns can vary in males and females. Studying individuals with autoimmune rheumatic diseases (ARD), Mariz et al. [37] found that more than positivity itself, ANA patterns are a crucial distinctive parameter between healthy and ARD affected individuals. Although other patterns could be found in healthy subjects, HN and NCPS patterns were found exclusively in ARD patients.
Since CD is frequently associated with other immune diseases, the presence of ANA in this population could be due to the concomitant occurrence of other diseases. Furthermore, being CD a condition with autoimmune characteristics, ANA test in CD individuals may be understood not only as a screening approach to evaluate at-risk individuals for developing other disorders, but also as a marker of the adaptive autoimmunity in CD. To help to clarify this point, the concomitant presence of other autoimmune conditions, especially regarding to those associated with the nuclear ANA patterns found here, should be investigated following. Based on the few and controversial available data, ANA-HEp-2 positivity in $\mathrm{CD}$ patients constitute an open field of investigation regarding its titers and staining patterns.

\section{Conclusion}

This study describes an $8.7 \%$ rate of ANA positivity among biopsy-proven celiac individuals in our population, and a not yet reported ANA staining pattern distribution among them. The actual meaning of ANA positivity among CD individuals, how to interpret its values and how to use them are yet to be understood.

\section{Funding}

This research did not receive any specific grant from funding agencies in the public, commercial, or not-for-profit sectors.

\section{References}

1. Rostom A, Murray JA, Kagnoff MF (2006) American Gastroenterological Association (AGA) Institute technical review on the diagnosis and management of celiac disease. Gastroenterology 131(6): 1981-2002.

2. Sollid LM, Lundin KE (2009) Diagnosis and treatment of celiac disease. Mucosal Immunol 2(1): 3-7.

3. Harris LA, Park JY, Voltaggio L, Lam Himlin D (2012) Celiac disease: clinical, endoscopic, and histopathologic review. Gastrointest Endosc 76(3): 625-640.

4. Datta Gupta S (2013) Pathology of celiac disease: a brief review. Trop Gastroenterol 34(4): 207-226.

5. Stamnaes J, Sollid LM (2015) Celiac disease: Autoimmunity in response to food antigen. Semin Immunol 27(5): 343-352.

6. Ventura A, Magazzù G, Greco L (1999) Duration of exposure to gluten and risk for autoimmune disorders in patients with celiac disease. SIGEP Study Group for Autoimmune Disorders in Celiac Disease. Gastroenterology 117(2): 297-303.

7. Ciccocioppo R, Kruzliak P, Cangemi GC, Miroslav Pohanka, Elena Betti, et al. (2015) The Spectrum of Differences between Childhood and Adulthood Celiac Disease. Nutrients 7(10): 8733-8751.

8. Vilppula A, Kaukinen K, Luostarinen L, Krekelä I, Patrikainen H, et al. (2009) Increasing prevalence and high incidence of celiac disease in elderly people: a population-based study. BMC Gastroenterol 9: 49. 
9. Vivas S, Vaquero L, Rodríguez Martín L, Caminero A (2015) Agerelated differences in celiac disease: Specific characteristics of adult presentation. World J Gastrointest Pharmacol Ther 6(4): 207-212.

10. Reilly NR, Husby S, Sanders DS, Green PHR (2018) Coeliac disease: to biopsy or not? Nat Rev Gastroenterol Hepatol 15(1): 60-66.

11. Van der Windt DA, Jellema P, Mulder CJ, Kneepkens CM, van der Horst HE (2010) Diagnostic testing for celiac disease among patients with abdominal symptoms: a systematic review. JAMA 303(17): 1738-1746.

12. Egner W, Shrimpton A, Sargur R, Patel D, Swallow K (2012) ESPGHAN guidance on coeliac disease 2012: multiples of ULN for decision making do not harmonise assay performance across centres. J Pediatr Gastroenterol Nutr 55(6): 733-735.

13. Murch S, Jenkins H, Auth M, Ronald Bremner, Assad Butt, et al. (2013) Joint BSPGHAN and Coeliac UK guidelines for the diagnosis and management of coeliac disease in children. Arch Dis Child 98: 806-811.

14. Satoh M, Vázquez Del Mercado M, Chan EK (2009) Clinical interpretation of antinuclear antibody tests in systemic rheumatic diseases. Mod Rheumatol 19(3): 219-228.

15. Wandstrat AE, Carr Johnson F, Branch V, Gray H, Fairhurst AM, et al (2006) Autoantibody profiling to identify individuals at risk for systemic lupus erythematosus. J Autoimmun 27(3):153-160.

16. Li QZ, Karp DR, Quan J, Branch VK, Zhou J, et al. (2011) Risk factors for ANA positivity in healthy persons. Arthritis Res Ther 13(2): 38.

17. Satoh M, Chan EK, Ho LA, Rose KM, Parks CG, et al. (2012) Prevalence and sociodemographic correlates of antinuclear antibodies in the United States. Arthritis Rheum 64(7): 2319-2327.

18. Agmon Levin N, Damoiseaux J, Kallenberg C, Sack U, Witte T, et al. (2014) International recommendations for the assessment of autoantibodies to cellular antigens referred to as anti-nuclear antibodies. Ann Rheum Dis 73(1): 17-23

19. Dellavance A, Gabriel Júnior A, Cintra AFU, Antônio Carlos Ximenes, Barbara Nuccitelli, et al. (2003) II Brazilian Consensus on Antinuclear Antibodies in HEp-2 Cells Definitions for standardization of autoantibody testing against the nucleus (ANA HEp-2), nucleolus, cytoplasm and mitotic apparatus, as wel as its clinical associations Rev Bras Reumatol 43(3): 129-140.

20. Chan EK, Damoiseaux J, Carballo OG, Conrad K, de Melo Cruvinel W, et al. (2015) Report of the First International Consensus on Standardized Nomenclature of Antinuclear Antibody HEp-2 Cell Patterns 2014-2015. Front Immunol 6: 412.

21. Pisetsky DS (2017) Antinuclear antibody testing - misunderstood or misbegotten? Nat Rev Rheumatol 13(8): 495-502.

22. Sulli A, Ruaro B, Smith V, Carmen Pizzorni, Giuseppe Zampogna, et al. (2013) Progression of nailfold microvascular damage and antinuclear antibody pattern in systemic sclerosis. J Rheumatol 40(5): 634-639.

23. Da Rosa Utiyama SR, da Silva Kotze LM, Nisihara RM, Roberta Ferreira CarvalhoElisandra Grangeiro de Carvalho, et al. (2001) Spectrum of autoantibodies in celiac patients and relatives. Dig Dis Sci 46(12): 2624 2630

24. Caglar E, Ugurlu S, Ozenoglu A, Gunay Can, Pinar Kadioglu, et al. (2009) Autoantibody frequency in celiac disease. Clinics (Sao Paulo) 64(12): 1195-1200.

25. Carroccio A, D’Alcamo A, Cavataio F, Soresi M, Seidita A, et al. (2015) High Proportions of People With Nonceliac Wheat Sensitivity Have Autoimmune Disease or Antinuclear Antibodies. Gastroenterology 149(3): 596-603

26. Pham Short A, Donaghue KC, Ambler G, Phelan H, Twigg S, et al. (2015) Screening for Celiac Disease in Type 1 Diabetes: A Systematic Review. Pediatrics 136(1): 170-176.

27. Iltanen S, Collin P, Korpela M, Holm K, Partanen J, et al. (1999) Celiac disease and markers of celiac disease latency in patients with primary Sjögren's syndrome. Am J Gastroenterol 94(4): 1042-1046.

28. Sategna Guidetti C, Bruno M, Mazza E, Carlino A, Predebon S, et al. (1998) Autoimmune thyroid diseases and coeliac disease. Eur J Gastroenterol Hepatol 10(11): 927-931.

29. Kaukinen K, Collin P, Mykkänen AH, Jukka Partanen, Markku Maki, et al. (1999) Celiac disease and autoimmune endocrinologic disorders. Dig Dis Sci 44(7): 1428-1433.

30. Caprai S, Vajro P, Ventura A, Marco Sciveres, Giuseppe Maggiore (2008) Autoimmune liver disease associated with celiac disease in childhood: a multicenter study. Clin Gastroenterol Hepatol 6(7): 803-806.

31. Hastier A, Patouraux S, Canivet CM, Lebeaupin C, Tran A, et al. (2016) Nonalcoholic steatohepatitis cirrhosis and type 1 refractory celiac disease: More than a fortuitous association? Clin Res Hepatol Gastroenterol 40(1): 4-5.

32. Volta U, Caio G, Tovoli F, De Giorgio R (2013) Gut-liver axis: an immune link between celiac disease and primary biliary cirrhosis. Expert Rev Gastroenterol Hepatol 7(3): 253-261.

33. Ludvigsson JF, Rubio Tapia A, Chowdhary V, Murray JA, Simard JF (2012) Increased risk of systemic lupus erythematosus in 29,000 patients with biopsy-verified celiac disease. J Rheumatol 39(10): 1964-1970.

34. Park SW, Park SJ, Shin JI (2013) Another possible underlying mechanism for the positive association between celiac disease and systemic lupus erythematosus: the role of interleukin 21. J Rheumatol 40(9): 1619.

35. Cojocaru M, Cojocaru IM, Silosi I (2010) Multiple autoimmune syndrome. Maedica (Buchar) 5(2): 132-134.

36. Li YR, Li J, Zhao SD, Bradfield JP, Mentch FD, et al. (2015) Meta-analysis of shared genetic architecture across ten pediatric autoimmune diseases. Nat Med 21(9): 1018-1027.

37. Mariz HA, Sato EI, Barbosa SH, Rodrigues SH, Dellavance A, et al. (2011) Pattern on the antinuclear antibody-HEp-2 test is a critical parameter for discriminating antinuclear antibody-positive healthy individuals and patients with autoimmune rheumatic diseases. Arthritis Rheum 63(1): 191-200.

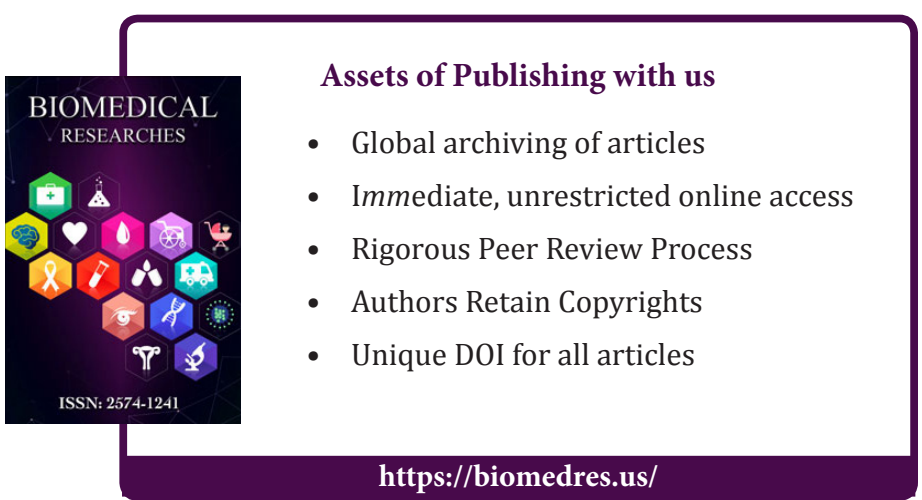

ISSN: 2574-1241

DOI: $10.26717 / B J S T R .2019 .13 .002418$

Yanna KM Nóbrega. Biomed J Sci \& Tech Res

This work is licensed under Creative

Commons Attribution 4.0 License

Submission Link: https://biomedres.us/submit-manuscript.php 